Por: Juan Enrique Silva B. $\left({ }^{*}\right)$

I.- EL DERECHO DEL ESTADO SOBRE LAS MINAS Y SU EJERCICIO.

1. - Su naturaleza jurídica.

Corresponde analizar con detenimiento la vin culacion que el derecho ha establecido - con más propiedad, el constituyente- entre el Estado y las minas, las consecuencias que se desprenden de tal vínculo.

La relacion elegida por el constituyente pa ra vincular al Estado con las minas, ha sido la de dominio. Este dominio es de orden patrimonial, esto es, de la misma naturaleza y caráter que el definido por el articulo 582 del Có digo Civil. En consecuencia, este dominio integra o se encuen tra en el activo patrimonial dél Estado.

Lo aseverado anteriormente no puede dejar lugar a dudas, ya que el sentido es el mismo que demuestra cla ramente la historia fidedigna del establecimiento de la ley. La afirmacion de que el vínculo del Estado con las minas de

(*). - De su Memoria de Prueba para optar al Grado de Licenciado en Ciencias Jurídicas y Sociales titulada "LA RELACION JURIDICA MINERA EN LA CONSTITUCION POLITICA DEL ESTADO DE 1980", dirigida y corregida por el Profesor Carlos Ruiz B. 
que trata la Carta Fundamental

es un dominio patrimonial perfecto surge, necesariamente, a consecuencia de que hoy en día existe una nueva concepción de dominio -que tuvo su ort-: gen en las preocupaciones interpretativas habidas con motivo de la preparación de la Ley Orgánica Constitucional sobre con cesiones mineras- que sustenta, con argumentos de variada naturaleza, que la relación del Estado con las minas, no sería el afirmado más arriba, sino que éste sería un "dominio subsi diario". A esta singular concepción se le dedicarán algunas lineas en lo que sigue, por cuanto se considera novedosa en lo que atañe a la forma de su construcción y al analisis de sarrollado para su decantación.

El caracter patrimonial del dominio que el Estado detenta sobre todas las minas se confirma, entre otras cosas, por la debida atención a las observaciones que siguen, las cuales, por la polaridad de las tendencias que estuvieron en disputa, no pueden dejar lugar a dudas sobre el sentido y naturaleza de 10 afirmado por el constituyente. Ellas dicen relación con:

1. - Lo establecido en el mensaje con que se acompaño el proyecto de ley de reforma constitucional -que posteriormente genero la ley número 17.450 , de 16 de Julio de 1971- en lo que dice relación con los fundamentos de los inci sos agregados al articulo $10^{\circ}$ numero 10 de las disposiciones permanentes de la Constitución de 1925. No obsta a la vali dez de lo apuntado anteriormente el hecho de que afirmaciones vertidas en aquella ocasión, y que resultan de caracter margi nal en la actualidad, estuvieran alejadas ostensiblemente de la realidad, tal como la supuesta unanimidad de pareceres en la doctrina, en lo que decía relación con la naturaleza del dominio del Estado sobre las minas segun interpretación funda Inentada en los artículos 591 del Codigo Civil y $1^{\circ}$ del Codigo de Minería de 1932.

2.- Lo que se disponía en el texto del proyecto de Acta Constitucional Tercera - Decreto Ley $\mathrm{N}^{0} 1.552$, de 18 de Septiembre de 1976- en cuanto prescribia que el Esta do tenía sobre las minas un "dominio eminente". El texto legal que se publico, en definitiva, prescribio sobre la mate ria, unicamente: "Un estatuto especial regulará todo lo con cerniente a la propiedad minera'!.. etc., variando as1, osten siblemente, lo que se propuso como texto de Acta Constitucio= nal, proyecto que el poder constituyente rechaz6 en este punto.

3.- Lo que disponia el texto del anteproyec to de la nueva Constitución, preparado por la C.E.N.C. (*), àl

(*). - Comisión de Estudios de la Nueva Constitución. 
disponer sobre la materia, que el Estado tenla una "propiedad eminente" sobre todas las minas.

4.- Lo dispuesto en el texto del anteproyec to de la nueva constitución, una vez que informo sobre él el Consejo de Estado. En el aspecto que nos interesa, el criterio de la C.E.N.C. se mantuvo idéntico.

5.- Lo dispuesto, en forma definitiva, sobre la materia en la Carta que actualmente nos rige:, al establecer en una forma idéntica a la Carta de 1925, reformada en 1971, que el Estado tiene el dominio absoluto, exclusivo, ina lienable e imprescriptible de todas las minas. De esta manera el poder constituyente reitera su voluntad sin solucion de con tinuidad-disposiciones transitorias del Decreto Ley 1.552, a $\bar{r}$ trculo $4^{\circ}$ - haciendo suyas, en esta nueva manifestación de volun tad, todo lo obrado en virtud de la ley 17.450 y rechazando, nuevamente, la idea establecida en los proyectos de que se ha dado cuenta, de asignar al Estado un mero "dominio eminente" sobre todas las minas.

E1 desarrollo de la historia fidedigna del :: establecimiento de la voluntad del constituyente, ha sido más que elocuente en ilustrar el criterio sobre la materia. Ya en el texto positivo, son concluyentes las expresiones por medio de las cuales el constituyente caracterizb la vincula ción, afirmando las caracteristicas más señaladas que acompañan al dominio patrimonial -exclusivo, absoluto- án cuando no hubiere sido necesario, pero que estimo preferible dejar fehacientemente establecido para hacer más indubitable su voluntad.

\section{2.- Caracteristicas.}

La Carta Fundamental señala que el dominio del Estado sobre las minas es absoluto. Es una acepción tradicional, ello puede significar dos cosas, no siendo excluyentes ambos sentidos. En primer lugar, que el dueño -en este caso el kstado- puede ejercer todas las facultades posibles que este derecho sea sus ceptible de otorgar -materiales y juridicas- $y$, en segundo $1 \bar{u}$ gar, que estas facultades las puede ejercer el titular en for ma discrecional, sin que nadie pueda entrabar la decision res pectiva, pero, dentro de los limites naturales del mismo, es= to es, la ley y el derecho ajeno. El articulo 582 del Código Civil, as 10 áispone al establecer que el dominio faculta pa ra gozar y disponer arbitrariamente de la cosa, no siendo con tra ley o derecho ajeno. En lo que atañe a la facultad juri= dica de disposición, ésta se encuentra limitada, en el mismo texto constitucional, al señalarse seguidamente, que este dominio sobre todas las minas, es inalienable, en cuanto se pue 
da entender que se ejerce sobre el yacimiento $y$ en la medida que el unico acto de disposición consentido por el constitu yente, es el otorgamiento del derecho de "concesión".

En la actualidad se ha sustiturdo el caracter absoluto del dominio, por el de la "generalidad" e "independencia" , indicandose con respecto a la primera expresión, que esta autoriza al titular para aprovecharse de todas las utilidades que el objeto es susceptible de proporcionar $y$, en cuanto a la segunda expresion, que existe por si solo, no requiriendo para su existencia de ningun otro derecho concurren te u original. (*)

Seguidamente, la Carta Fundamental señala que el dominio del Estado es exclusivo. Con ello se quiere significar, de acuerdo al lenguaje técnico juríaico, que el dominio supone naturalmente un tinico titular, sea éste una persona natural o juridica, privada o pública, nacional o extranjera, habilitado para usar, gozar y disponer de la cosa sobre la cual recae el dominio o sobre el mismo, como cosa incorporal.

Implicito en el carácter exclusivo, y esto es por ser el otro aspecto del caracter mencionado, se encuen tra la caracteristica de ser un derecho excluyente. Esto es asi, en atención a que la exclusividad quiere significar que una sola persona puede ser titulax, pudiendo excluix a cual.quier tercero, no permitiéndole la intromisión en su esfera jurídica.

Queda claro que ninguna persona, sea de la especie que fuere, podra vincularse dominicalmente con las mi nas; a ello se opone el caracter de ser un derecho exclusivo: $y$, por tanto, excluyente de cualquier otro interesado.

También, el texto constitucional menciona que el dominio del Estado tiene el caracter inalienable. E110 quiere significar que el objeto sobre el cual recae - las minas- no pueden ser enajenadas. En consecuencia, con respec to a ellas, no puede existir ni ejecutarse por el Estado ningun acto que, en forma directa o indirecta, provoque la enaje nación o sus efectos. Ello es asi por cuanto existe mandato expreso de la Constitución y, ademas, porque la caracteristica mencionada no pertenece esencialmente sino naturalmente al dominio $y$, en este dominio estatal ha pasado a ser una ca-

(*).- Véase al respecto; "Curso de Derecho Civil" de A. Alessandri R. y M. Somarriva U., redactado por A. Vodanovic Edit. Nascimiento, 1972 , cuarta edición, págs. 138 y ss.- 
racterIstica o elemento esencial de dicho dominio.

Se concluye, de acuerdo con lo señalado anteriormente, que el Estado, en el afán de darle el destino na tural a las minas, no podra utilizar instrumentos jurídicos tales como arrendamientos de plazo indefinido, enajenaciones, en aporte a sociedades, ventas $y$, en general, utilizar los medios concebidos y relacionados a proposito del "sistema regalista".

En suma, encontrándose en el patrimonio del Estado estos bienes -elementos activos-, no son susceptibles de acto alguno sobre ellos que implique enajenación (*), y cons tituyen, por tanto, la categoría de bienes llamados "incomer ciables".

Como consecuencia de esta caracteristica, las personas, sean éstas naturales o juridicas, de derecho pri vado, o publico diferente del Estado, nacionales o extranjeras, no pueden adquirir el dominio de las minas.

Pareciera que la caracteristica que se comenta, estuviera, en cierto modo, de más; por cuanto, por la inalienabilidad que la precede, estaría -en terminos absolutos y definitivos, dada la categoría de la norma por medio de la cual se expresa- fuera de la posibilidad de ser objeto de relaciones jurldicas privadas, pertenenciendo a la categoria de blenes denominaóos "incomerciables". Con respecto a ellos, no podrla existir juridicamente "posesion", elemento indispen sable para que proceda la prescripción adquisitiva.

No mencionadas expresamente por el constitu yente, pero por acompañar siempre al dominio de una manera indefectible, se pueden señalar las siguientes caracteristicas adicionales del dominio del Estado sobre las minas.

a) Es un dominio perpetuo. Con ello se quie re significar, que no esta, en su existencia, sujeto a factores o limitaciones - como el factor tiempo en la propiedad fiduciaria, articulo 733 del codigo Civil-y dura cuanto dure la cosa sobre la cual se ejerza. Se añade que, en sí mismo, no lleva una razón de caducidad $(* *)$, y subsiste independien temente del ejercicio que pueda hacerse de él.

(* ). - Esta afirmación, debe entenderse con la salvedad del acto "concesión", en cuanto se la considere "acto de disposición", por permi tir la apropiación de los minerales que conforman el yacimiento.

$(* *)$. - Caducidad es la circunstancia que de acaecer en el curso de la existencia de un derecho, destruye tal derecho o vínculo, provocando su extinción. 
Lo anterior se avala por los caracteres de orden excepcional que $1_{0}$ acompañan y de los cuales se hace men ción expresa: "la inalienabilidad" y la "imprescriptibilidad"del derecho de dominio del Estado sobre las minas.

Por existir propiedades temporales o sujetas a condición -la propiedad fiduciaria, articulo 733 en relacion al 739 del Codigo Civil- se dice que, en vez de "perpetuidad" del dominio, mas precisamente, debería indicarse que el dominio es "generalmente perpetuo" ya que la perpetuidad pasa a ser de la naturaleza pero no de la esencia del dominio. Al respecto, pareciera ser prudente señalar que el dominio que el Estado detenta sobre todas las minas y de que trata la Cons titución, tendría como factor esencial, la perpetuidad del mis mo. Lo anterior se reafirma, por el hecho de que siendo una relacion o vínculo principal -derechos reales principales o en cosa propia; el dominio, la herencia- no esta sujeto a la temporalidad implicita de los otros derechos - derechos reales accesorios o en cosa ajena (ius in re aliena); usufructo, el uso y la habitación, la prenda y la hipoteca en el Codigo Civil y en el Codigo de Mineria, la concesión exclusiva para ex plorar de que trata el artículo 25 letra b)- abonado por las caracteristicas de orden excepcional ya mencionadas y que expresamente le acompañan.

b) El dominio es abstracto. Mediante ello, se quiere significar que tiene una existencia independiente $y$, por tanto, distinta de las facultades que contiene y otorga -idea del patrimonio en relación a los elementos activos y pa sivos que lo integran y que no se confunden con su entidad-. Se explica la aseveracion señalando que, aln cuando exista otro derecho concurrente (ejemplo: derecho de usufructo), el dominio, como dominio que es, permanece idéntico a si mismo, $y$ las facultades que entraña el derecho concurrente, (ej. del Caso: uso y gocel, permanecen "potencialmente" en su entidad, en que sólo el ejercicio de aquellas facultades, pasa a manos del titular del derecho concurrente (el usufructuario).

\section{c) E1 dominio es elástico. Con ello se} quiere significar que naturalmente puede ejercerse con todas las facultades que otorga, pero que bien puede limitarse esta amplitud o ser restringido por otro derecho concurrente, en mayor o menor medida. Pero, siendo la primera una vincula ción principal, por criterio de exclusión, los fnicos que con currirán serán los derechos reales en cosa ajena, que por su temporalidad implicita $y$ una vez que lleguen a extinguirse, en forma "automatica" y sin necesidad de acto posterior, se volverán a reunir todas las facultades en forma plena, como lo era en su estado original. 
Las anteriores caracteristicas permitirán, de un modo más preciso, acercarse a verificar la naturaleza del derecho que se prescribe para el concurso de los particu lares, como también la determinación del objeto sobre el cual recae $y$ se ejerce $y$ de que tratan los incisos séptimo, octavo $Y$ noveno del $\mathrm{N}^{\circ} 24$ del artículo 19 de la Carta Fundamental.

Revisadas las caracteristicas tanto positivas como doctrinarias que reviste la vinculación dominical del Estado con las minas - que no son otras que las formuladas generalmente para el dominio civil, bajo el consenso de que se trata de una relación de derecho privado, a que se refiere el artrculo 582 del Codigo Civil- corresponde ocuparse de la concepción denominada "dominio subsidiario" que, como nueva tesis nacida en estos dias, trata de precisar el verdadero al cance $y$ sentido que tendría en la constitución vigente, el de recho del Estado sobre las minas.

Por de pronto, debe tenerse presente que las vinculaciones reales -el dominio es la más importante en extension e intensidad-conocidas desde los tiempos del dere cho romano, poco o nada han variado hasta nuestra época $y$ sర lo lo han hecho de modo incidental, para adecuarse a las moEi vaciones $y$ tendencias sociales contemporáneas que han influi= do en su reformulación, pero, esencialmente, son las mismas que conocio Roma.

En materia de dominio, $y$ desde una perspectiva puramente ideal, se ha conocido el tradicional "dominio quiritario" (articulo 582 del codigo Civil), "I a propiedad fiduciaria" (articulo 733 del mismo cuerpo legal) y surge una nueva noción, en estos altimos tres siglos, el 1lamado "dominio eminente", cuya formulación naturaleza y contenido escapa a los parametros del derecho privado, ya que aquel concepto es una consecuencia o manifestacion de la soberania de los Estados nacionales, en cuanto, por medio de 61 , se permite dis poner, en el evento necesario, de todo cuanto se halle dentro de sus fronteras. Dicha noción es tomada en el derecho inter no, más precisamente en Derecho de Mineria, para explicar la relación de dominio del Estado con las minas, segun interpre tacion de lo dispuesto en los artŕculos 591 del Codigo CiviI $y 1^{\circ}$ del Codigo de Minería, entre otros. Se conocen otras expresiones analogas a la de dominio eminente, pero esta vez en referencia o teniendo como marco exclușivo el Derecho de Minerra, siendo ellas la de "dominio originario", "dominio ra dical", "dominio eminente ".

3.- El dominio subsidiado.

Como ya se apuntaba anteriormente, la tesis 
del dominio subsidiario surge en nuestros días para explicar, bajo una perspectiva de novedad, la naturaleza, sentido y contenido de la relación del Estado con todas las minas de que trata la constitución, particularmente en el numero 24 , inciso sexto, del articulo 19 .

La relevancia jurídica de esta nueva posi ción surge del hecho de que fue expuesta con motivo de la dic tación de la ley orgánica constitucional sobre concesiones mi= neras, en el seno $y$ desarrollo de su formulación, interpretacion que formo parte del "informe técnico" acompañado a tal iniciativa legal, esto es, como fundamento del proyecto de ley referido.

Como primer punto, debe hacerse presente que las expresiones utilizadas para su ilustración no resultan del todo díffanas. Ello, debido quizas -esta observación es una mera especulación- a que su sostenedor no pareciera utilizar, en propiedad, expresiones y conceptos de significacion precisa en técnica jurı́lca, tornando, de este modo, confusas las explicaciones dadas ante cada aseveración. Todo esto pareciera provenir de la premura de su construcción Y, además, por otro lado, a las complejidades que conciernen a las instituciones del Derecho de Minería que requieren, de un modo cierto, de una mayor capacidad de abstracción del interprete interesado en su cabal e Integra comprensión.

For 10 que atañe a la exposición misma, la sóla expresion "dominio subsidiario" conduce a confusión. Ya se ha anotado que el dominio es un derecho real de los califi cados principales y sobre cosa propia -dominio que también sé llama propiedad-, como elemento diferencial sobre los otros derechos reales sobre cosa ajena - ius in re aliena- y los de caráter accesorio. De ello surge la consecuencia de ser el dominio un derecho absoluto, exclusivo y excluyente.

La expresión "subsidiario", en el sentido más generalizado que pueda darse, evoca la idea de una cosa que "es" o que "puede darse" a consecuencia de que otra cosa "no fue" o "no pudo darse". De esta manera se comprende, cuan do se expresa que una cosa, acción o situación "es en subsidio de otra". En el mismo sentido puede entenderse la expli cacion del "principio de subsidiariedad" y la accion subsecūen te que $e l$ promueve desarrollar (*), al señalarse: "La 6rbita de competencia de la sociedad mayor -El Estado- empieza donde termina la posioilidad de acción adecuada a la menor -el hombre como unidad, la familia y las demás agrupaciones humanas intermedias-. De lo anterior resulta que su entidad

(*).- "Declaración de Principios de1 Gobierno de Chile". Stgo., Marzo de 1974, págs. 16 y ss. 
es accesoria, no queriendo significar aquello que sea mas o menos importante desde una optica de valor.

De 10 anterior resulta, dadas las caracteristicas que acompañan al dominio en la inteligencia anterior, que la adjetivación del dominio con tal expresión, pareciera ser inadecuada, porque, tratando de constituir un concepto uni tario -para lo que se quiere expresar con ello- se emplean tér minos excluyentes, esto, por el hecho de que la existencia de una (el dominio) impide la afirmación y vigencia contemporánea de la otra ("subsidiario") y viceversa.

De la misma manera, si se tiene que es un "dominio subsidiario" -"en subsidio de" o bien, que sus facul tades son de intensidad periférica, excéntricas ó de excepción, como resulta del sentido que puede obtenerse con una interpretación general -pareciera necesario, por imperativo 16gico-ele mental de la construcción, referirse al dominio de carácter "principal", al que es antes de ser subsidiario o al tiempo de este, como lo requiere el contexto de sus explicaciones. Y, si con esta categoría no se cuenta, lo que se deduce de la so la lectura de la exposición de la tesis del dominio subsidia= rio, pareciera no ser prudente sostener la existencia de tal derecho de dominio, de orden secundario o accesorio, sin que cambie de naturaleza y se constituya en principal por elemental exigencia logica: Todo ello es consecuencia de que lo que es "subsidiario" en sentido general, debe entenderse naturalmente en una acepcion juridica, como "accesorio".

Todo lo anterior, en definitiva, demuestra la severa contradicción de orden elemental que asiste a la expresión "dominio subsidiario", en la construcción utilizada para su formulación.

Despues de habernos detenido en un aspecto :formal, como 10 es la particular designación de la tesis que se comenta $Y$, una vez hechas las observaciones respectivas, corresponde detenerse en el aspecto de fondo, en su contenido.

a) En lo substancial, la tesis del dominio subsidiario del Estado sobre el objeto jurŕdico "mina ", como expresion de las normas constitucionales sobre la materia, se decide en las siguientes aseveraciones:

- Que el dominio que detenta el Estado sobre estos bienes no es de Indole privada, como es aquel que trata el codigo Civil en el articulo 582, sino, que es un dominio de naturale za "publica", por lo que se distingue del dominio privado $\bar{y}$ que en el contexto de las normas fundamentales es un "dominio subsidiario". 
- Que este dominio "subsidiario" del Estado tiene por objeto "la riqueza minera", esto es, "todas las minas" (*), lo que quiere significar: "Toda la riqueza potencialmente existente en el territorio nacional". $\left({ }^{* *}\right)$

- Que una vez descubiertas las minas, el Éstado "conserva su derecho" y que las caracteristicas del dominio, en tal evento, "no son todas las del dominio civil, 10 que se demuestra con el texto del numero 24 del artículo 19 de 1 a Constitucion".

- Que la diferencia más señalada en este dominio del Estado, es que "sobre la propia mina" un particular puede constituir concesión que le pertenece en régimen de propiecad privada, que incluye las facultades de uso, goce y disposición de tal derecho, sin necesidad de que el Estado "exprese voluntad traslaticia de derechos" que sirva al particular de titulo para adquirir la concesión.

- El poder judicial "reconoce" al titular legitimo un ple no dominio civil sobre la concesión, en resolución de natu= raleza "meramente declarativa" antes que "constitutiva".

- La diferencia queda remarcada -entre el dominio público sobre las minas y el privado sobre las concesiones mineraspor la "inalienabilidad" del dominio estatal.

- Consecuencia de lo anterior, es que el Estado se encuentra en la calidad de "mero depositario" de la "riqueza minera" de la nación, sin que se permita al mero arbitrio de "la au toridad publica" entregarla en concesión administrativa a los particulares.

- Que el derecho de goce sobre las sustancias minerales no emana del de dominio del Estado sobre las minas, sino que solo puede derivar de una "concesion minera" sobre sustancias concesibles, o de la ley que declare la concesibilidad de una sustancia.

- Consecuencia de todo 10 anterior es que el dominio del Estado no supone las facultades ordinarias que conlleva el do minio de naturaleza privada -uso, goce $y$ disposicion- sino. que es un derecho que se ha calificado de dominio por dos razones fundamentales, siendo ellas: la mantencion de una relación excluyente de todo interés privado que no se funde en una concesion constituida, $y$ el reintegrar al dominio es

(* ).- José Piñera Echeñique, en ob. cit., pág. 34.

(**) .- ob. cit.; pág. 35 segundo párrafo. 
tatal los "atributos que otorga la concesión", una vez que és ta se extingue, para los efectos de dejarlos disponibles, bajo el supuesto de que se trata de sustancias concesibles, a., los nuevos particulares interesados en vincularse en la cali-s dad que se ha indicado.

b) En lo que dice relación con el contenido del derecho de dominio "subsidiario" del Estado sobre todas las minas, este adquirirla significacibn de acuerdo a las siguientes premisas, dadas en la Carta Fundamental;

- Señalar una "tuición subsidiaria, general y permanente soi,bre todas las minas", cuyo objetivo primario es darse una normativa especial que trasunte una politica minera.

- Permitir la creación y constitución de derechos mineros que emanan directamente de la ley $Y$ que resultan ser distintos de la propiedad de los terrenos donde se encuentran las minas.

- Reconocer originariamente derechos mineros anteriores al des cubrimiento de las minas.

- Reconocer el nacimiento de los derechos particulares a explo rar y explotar las minas mediante un "acto propiamente declarativo", antes que "constitutivo", que patentiza el Estado mediente de la constatación de haberse cumplido las exigencias legales, cometido, que, incluso, se entrega a los tribunales $y$, por fltimo,

- Recuperar la facultad de reconocer derechos de concesion minera en caso de incumplimiento de la condición de amparo por los concesionarios anteriores.

c) Sobre los caracteres que acompañan al dominio "subsidiario" del Estado, se señala lo siguiente:

- Que el caracter "subsidiario" le permite mantener a perpetui cad una tuición general sobre los derechos mineros. La permanencia nace $y$ se expresa ante el hecho de que el dominio ajel Estado coexiste con las facultades reconocidas a los par ticulares $y$ que puede "hacerse presente siempre", originariā mente, cuando se den las condiciones impuestas por la ley.

- Que el dominio del Estado sea absoluto indica que éste, el Estado, lo tiene de una manera general, resuelta $y$ terminante, que no esta sujeto a relación ni dependencla alguna, em pleada la expresion, según el decir del expositor de la te sis, "en el sentido que le da el diccionario". 
- Que el doininio del Estado sea exclusivo indica que Éste es el unico, que lo tiene sరlo el, y que excluye especialmente al propietario del suelo en cuanto tal.

- Que el dominio del Estado sea inalienable, significarfa que el Estado 10 conserva permanentemente tanto sobre las minas ya descubiertas como sobre aquellas que no lo han sido aun.

- Que el dominio del Estado sobre todas las minas sea imprescriptible quiere decir, segun el autor, que el Estado no pue de perder este dominio por el mero transcurso del tiempo, siendo irrelevante, al respecto, que los particulares tengan la posesion de dichas minas.

d) Por Ultimo, en cuanto a que el Estado pue da ejercer con respecto a las minas una relación "más cercana a1 objeto", esto es, llevar a efecto las facultades de uso y goce $y$, aun cuando no se menciona, la facultad de disposición, tendría tres caminos para lograr tal objeto, siendo ellos los siguientes: 1.- Obtener concesión minera sobre sustancia concesible. 2.- Mediante la declaracion de "no concesibilidad" que pueda afectar a ciertas sustancias, y 3.- Por la declaración de "zona de importancia para la seguridad nacional con los efectos del inciso décimo" de la norma constitucional que se comenta.

4.- Objeciones.

Con respecto a la teoría anterior, cuya exposición se ha hecho en forma sintetica, se puede decir lo siguiente: que ha quedado muy en claro, que el dominio del Esta do sobre todas las minas es patrimonial y pleno (*), tanto en la evolución de la voluntad del constituyente como en las for mas por medio cie las cuales se ha expresado. En consecuenciā, resulta en cierto modo excéntrico interpretar de otra manera la referida norma, en franca oposicion con el texto y el espr ritu de la preceptiva constitucional.

El cumulo de aseveraciones que se realizan, $Y$ que se suceden en una forma vertiginosa, hace fatigoso el examen detenido de cada una de ellas, por lo cual, en aten ción a la finalidad de este trabajo y por razones de exten sión, no se realizará aquél, sino en la medida elemental requerida para demostrar las premisas erroneas sobre la cual su construcción se asienta.

\section{Al efecto, se analizara una de las primeras}

(*).- La expresión "pleno", está tomada en oposición a la "nuda" o "desnuda" propiedad, de que trata el artículo 582, inciso segundo, del código Civil. 
aseveraciones que se hacen $y$ que es aquella en que su.sostenedor nos indica que el dominio del Estado es de naturaleza pública $y$ que, por ello, se distingue o differencia del privado, pasan do a ser "subsidiario" en las normas constitucionales.

De este modo, cabe preguntarse ¿en que se di ferencia un dominio piblico de un dominio privado? $y$, ademas, cen atención a que factor se califica si un dominio es publico o privado? $y$, por laltimo, cabe tambien preguntarse si el factor tomado en cuenta para calificar uno y otro dominio, ies gravitatorio para los efectos de una distincion de orden sustancial o, al contrario, es de orden puramente formal o acciden tal o de efectos, si se quiere, pedagogicos?

En cuanto a la primera pregunta, la tesis del dominio subsidiario -en adelante D.S., (*)-, se limita a aseverar que la diferencia existe, sin entrar en mayores expli caciones. Se concluye, consecuencia de la aseveración anterior, de que, por eso, se "distingue del dominio privado".

En atención a ello, se hace necesario indagar en qué consiste tal diferencia, fuera de la que es ya obvia, como resulta de los nombres dados $Y$ por los cuales se re conocen. Para adentrarse en su analisis, es previo determinār la respuesta a la seguna interrogante, esto es, apreciar el factor o elemento tomado en cuenta para calificar si un dominio es público o privado.

Al tratar de precisar el factor de diferenciacion nos encontramos con las siguientes posibilidades:

- Que el dominio sera publico, al considerar en forma exclusi va el hecho de que su tratamiento y reglamentación se reali cen por medio de normas juridicas de derecho público; y será privado, cuando su tratamiento, fundamentalmente, se rea lice por medio de normas jurldicas de derecho privado. (**T En este criterio se ha tomado en cuenta la naturaleza de la norma juridica que trata y reglamenta el dominio, por lo tanto, se le puede llamar criterio o factor "objetivo". Sin embargo, debe tenerse presente, que la diferenciacion misma entre normas de derecho público y normas de derecho privado o, lo que es lo mismo, derecho público y derecho privado

-y en especial el tratamiento y reglamentación del dominio $y$ demás derechos reales- no es del todo diafana en estos días,

\footnotetext{
(* ).- La sigla D.S., se utilizará cada vez que lo requiera la síntesis de la exposición.

(**) .- Véase:" Curso de Derecho Civil". Los bienes y los derechos reales, de A. Alessandri R. Y M. Somarriva U., págs. 103 y ss.
} 
por lo cual el uso de tal factor diferencial puede legitima mamente estimarse ciertamente inaplicable, en algunas situa= ciones.

- El otro criterio, verifica si el titular del derecho de domi nio es una persona de derecho publico o bien una persona de derecho privado. En consecuencia, representa el criterio "subjetivo", en contraposicion al anterior, que es de orden objetivo, sin perjuicio de lo anotado precedentemente a su respecto. Bajo esta óptica, resultara que el äominio va a ser público, cuando su titular sea el Estado o alguna otra entidad juridica menor que le represente -Municipalidades, por ejemplo-, y será privado, por criterio de exclusión, : cuando su titular sea cualquiera persona diferente del Estado o de las entidades menores que le representen.

Ahora bien, ¿cual es el criterio tomado en cuenta por la tesis del D.S.? Pareciera ser el criterio sub jetivo indicado anteriormente, por cuanto su construccion se realiza en atención exclusiva al sujeto que se considera por el constituyente: el Estado. Determinado el criterio de diferenciacion, en la medida que lo ha permitido el desarrollo de conjunto de la tesis que se comenta, corresponde determinar si tal situación hace que un dominio sea, en sustancia, diferente del otro.

Por de pronto, en la obra de los señores Ale ssandri y Somarriva, se señala que aunque los caracteres de 1a propiedad pública o de derecho publico no coinciden con los caracteres clásicos de la propiedad privada, en esencia, repre senta una forma de propiedad, como quiera que también es el poder más amplio que se puede tener sobre una cosa.

De modo que "los caracteres" son los diferen tes, aun cuando, en la obra citada, no se han precisado su en= tidad, naturaleza - en qué consisten-y numero, y resulta que esencialmente, institucionalmente, son lo mismo. De aquello, tendremos que las diferencias que se piedan encontrar son naturalmente de orden accesorio y no sustanciales o principales.

En efecto, si tenemos idealmente un dominio público y un dominio privado, ambos resultan ser "dominio" $y$, en consecuencia, otorgarán iguales facultades y poseerán igua les caracteres como tales, sin perjuicio de que concurran al= gunas caracteristicas de orden excepcional como es la incomer ciabilidad. Asimismo, habilitara a su titular-cualquiera que fuese y sea que se llame propietario fiduciario, usufructuario, usuario o habitador- para ejercer las acciones y dere chos tendientes a resguardar su integridad como tal derecho. 
En cuanto a la adjetivación del vinculo, es decir, de ser en un caso publico $y$ en el otro privado, según. sea la naturaleza de la norma o segan sea el sujeto que se vincule como titular, presentara, en todo caso, un caracter solamente accidental.

Ahora bien, el ejercicio de la voluntad o las formas por medio de las cuales se manifiesta, tendiente a actualizar o concretar las facultades que entraña el dominio, en un caso -en el dominio publico-, sera un proceso más complejo, $y$ en el otro caso -en el dominio privado- será un proceso menos complejo, pero complejo al fin. Asi, la voluntad del Estado deberá manifestarse por medio de las formas na turales mediante las cuales se expresa: la ley, un reglamento, el decreto supremo, la sentencia, etc. En definitiva, un "ac to juridico". Asimismo, el titular de un dominio privado requerira de un acto jurílico, cuya expresion sera relativamente simple en una persona natural y de una complejidad mayor en las personas juridicas (sociedades, fundaciones, corporaciones, etc.), equivalente, a veces, a las complejidades formales relacionadas con la expresión de la voluntad del Estado; mirada la complejidad desde un punto de vista exclusivamente jurIdico, desprovisto de apreciaciones comparativas de valor, ya sea moral, politico, ideologico u otros.

En lo que se refiere al ejercicio de las fa cultades, que son identicas en el uno y en el otro (uso, goce y disposición), no presenta mayores singularidades en el dominio privado, pero sí lo presentara en el dominio público. En efecto, si se tiene en cuenta que el Estado es la nacion jur dicamente organizada y que uno de los elementos de esta talti= ma -considerado el esencial- es el factor humano, esto es, la comunidad de hombres que hablan una misma lengua, poseen y re conocen un mismo pasado historico, unas mismas costumbres y habitan un territorio homogeneo o comun, resulta natural y no forzado que, siendo su entidad mayormente compleja, la titular del dominio pablico (artículos 589 y siguientes del codigo Civil), sea ella toda, y que todo su elemento humano sea el que ejerza las facultades más relevantes, como son el uso y goce, en los bienes sobre los cuales recaiga este dominio. Debido a esta circunstancia, serán numerosos e indeterminados los usuarios, rasgo que no se advierte en el dominio privado en que, a veces, siendo numerosos los usuarios - una fundacion, corporación, sindicato, etc.- son perfectamente determinados. Aun, se desdibuja esta singularidad, perdiendo relevancia, en relación a los llamados bienes nacionales, en la especie deno minada "bienes fiscales" (artículo 589 inciso 3 del codigo Cí vil), en que la facultad de uso ".... no pertenece generalmen te a los habitantes....", asimilándose, éstos en el uso y su ejế cicio, al que ejercen las personas jurídicas de derecho privādo. 
En cuanto al ejercicio de la facultad de dis posicion, requerira en ambos casos de un acto juridico, menos complejo en su formacion en las personas de derecho privado $y$ mayormente complejo en el Estado o personas de derecho publico, en que ésta se debera expresar en conformidad a la ley, que es "... una declaración de la voluntad soberana.... manifestada en la forma prescrita en la Constitucion." Al respecto, en la nueva Constitución politica se prescribe en el articulo 60 número 16, lo siguiente: "Sólo son materia de ley, .... las que fijen normas sobre enajenación de los bienes del Estado o de las municipalidades y sobre su arrendamiento y concesion.".

De esta manera, la singularidad que revista uno u otro dominio, solamente sera el numero de sujetos que ejerzan las facultades de uso y goce $y$ su correspondiente determinación, como, también, la generacion mayormente compleja de la voluntad cuando se trate del ejercicio de la facultad de disposicion.

Ante tocio esto, resulta que las diferencias que se pueden encontrar son nominales $y$ de orden accesorio, no siendo fundamentales como pareciera desprenderse de la afirmación que se comenta en la tesis del D.S. De esta manera, queda en claro que tal premisa no es suficiente, de acuerdo a una estricta tecnica juridica, para sostener la naturaleza diferente de un derecho, como es la presurosa conclusión a que se arriba por su sostenedor.

Como se anotaba anteriormente, constituiria una tarea de extension significativa la observación juriáica de cada una de las aseveraciones mediante las cuales se ex presa o se manifiesta la teoría del dominio subsidiario, lo cual, no se compadece con los limitados fines de este trabajo. Sin embargo, cabe destacar que los cinco puntos anotados por su sostenedor, relativos a las ideas matrices contenidas en la normativa fundamental (*), tienen una extraordinaria similitud con las finalidades u objetivos precisos en que se mate rializaba la teorla del "dominio eminente" del Estado sobre esta categoría de bienes.

En efecto, el dominio eminente del Estado consiste en un derecho permanente $y$ general sobre todas las minas, descubiertas o no, en el territorio nacional $y$ adquirla tonalidad en el derecho minero, al permitir la constitución de un aerecho originario en el patrimonio del sujeto particular, enajenacion que representaba una de las limitadas facultades, sino la linica, reconocidas a este dominio en ma-

(*).- José Piñera E., ob. cit., pãg. 37 y ss. 
nos del Estado. A su vez, a éste le permitia reconocer prerro gativas de los particulares anteriores al descubrimiento, taLes como las facultades de catear (catar) y cavar, además de constituir concesiones exclusivas con el objeto de buscar las minas que se pudieran encontrar en el territorio a que se referia el trtulo $y$, por altimo, recuperar esta facultad de cons tituir derechos de Indole privada, cuando sobrevengan causales de caducidad en los derechos de los particulares vinculados. El Estado, por su parte, para los efectos de constituir derechos patrimoniales -al igual que los sujetos particulares- so bre sustancias minerales que le interesaban, podra utilizar dos mecanismos, siendo estos: la declaración de reserva sobre determinadas sustancias, o bien la constitucion de pertenencia minera con la misma calidad $y$ en igualdad de condiciones con los particulares.

No obstante la certeza en algunas de las finalidades mencionadas -ellas corresponden a los objetivos de politica económica más generales de fomento, que tiende a rea lizar, como especialidad, la normativa minera- resulta ser, en lo demas, una grave impropiedad. Ello es asi, si se piensa que la mera interpretación que era el dominio eminente del Estado sobre las minas, ha dejado de tener lugar desde 1971 en nuestro derecho minero $y$ mal podrian sustentarse sus postu lados bajo un nuevo nombre, como es el de dominio subsidiario - identidad de aseveraciones y efectos- ante un derecho positi vo tan explícito $y$ reiterado, como también ante el claro senti do de la norma, que se desprende de una atenta consideración del äesarrollo de la historia fidedigna del establecimiento de la norma constitucional - De este modo la interpretacion particular que es en el plano de las ideas el "dominio subsidiario", ciertamente, constituye una aventura con resultados desventurados.

Es una aventura, por el hecho de que en su formulación existe una abierta desconsideración por el claro texto positivo de la norma sobre la cual se intenta o se pre tende discurrir, como, también, por la historia fidedigna de su establecimiento; elementos de que necesariamente debe hacerse uso, si se quiere presentar resultados armoniosos en la labor interpretativa. Es de resultados desventurados, por el hecho de que su sostenedor, en la construcción realizada, utiliza como categorías juridicas -que en cierto modo son absolutas por el lento proceso de perfeccionamiento en el curso de la historia (ejemplo: el dominio)- elementos e ideas propias de una contingente politica econbmica que se enmarca en una estrategia, entre muchas, en busqueda del anhelado desarrollo. Ello resulto evidente cuando se observo la calificación con que el autor de esta interpretación delimito - definio- la na 
turaleza del vínculo estatal.

También es una desventura, por cuanto actualiza a nuestros dias la vieja controversia acerca de la exacta determinacion del vínculo juridico del Estado con las minas, efecto que resulta ciertamente negativo ante la diafanidad, que, con prioridad, debe asistir a la institucion juridica mar co de estos comentarios. Con ello, subrepticiamente, se intrōduce un factor de perturbación en el lector desinteresado y ajeno al conocimiento de nuestro derecho de minerla.

5.- Efectos del derecho patrimonial del Estado.

Corresponde preocuparse, en las lineas que siguen, de los efectos que se pueden atribuir a la relación de dominio pleno o patrimonial que el Estado tiene con respec to a las minas.

A.- En primer lugar, cabe determinar, de a cuerdo a la naturaleza del derecho de dominio que se sustenta en este trabajo, si las minas son un bien fiscal o del Estado, de acuerdo a la clasificación realizada por los artículos 539 y siguientes del Codigo Civil, en el Trtulo III, "De los bie:nes nacionales". Antes de la Reforma Constitucional de 1971, la ubicación de las minas como bien nacional, siendo una espe cie diferente de las dos clases mencionadas en los respectivós incisos -segundo $y$ tercero- del citado artículo 589, resultaba de la interpretación, virtualmente unanime, de la doctrina y jurisprudencia. De aquella interpretación se colegra que la categorla de dominio que se prescribía en los incisos mencionados era de índole patrimonial, al contrario del que tra taba el artículo 591-que es identico al artículo $1^{\circ}$ del codí go de Minería de 1932 y los cuerpos legales antecesores-, en que se estimabaque era un dominio no patrimonial ("extrapatri monial"), bajo las denominaciones de "radical", "originario", "eininente", etc. Cabe señalar, que tal interpretación no se compadecía con el desarrollo logico y la estructura de los pre ceptos realizada por don Andres Bello. Lo anterior resulta de considerar de que en el Título que se comenta, solamente se ha tratado de dos clases o categorías de bienes nacionales; bienes nacionales de uso público y bienes del Estado o bienes fiscales. De modo, pues, que no ha estado $\mathrm{ni}$ en la sistemati ca ae los preceptos, $n i$ en la letra $Y$, presumiblemente, ni en el espiritu de su autor, el tratamiento de esta naturaleza de derecho de dominio. Cabe anotar que el concepto de "dominio eminente" pertenece propiamente a otro orden normativo, como es el Derecho de Gentes y, respecto del cual, existia por par te del autor del Código Civil especial versación, de modo que no resultaba ser prudente internar tal concepción, en des 
medro de su conocimiento, en un derecho especial interno.

Después de la reforma constitucional de 1971 , Llevada a cabo por la ley 17.450 , de 16 de Julio del mismo año, aparece con suficiente claridad que tal dominio es patrimonial $y$, por ser una interpretación auténtica, contextual, de propia autoridad, debe considerarse y entenderse, definitivamente, que el dominio previsto en el articulo 591 del Codigo Civil y $1^{\circ}$ del Codigo de Minerla, es y reviste el caracter de patrimonial $y$ pleno, desde siempre.

La expresión "tiene" utilizada por el consti tuyente -modo indicativo del tiempo presente del verbo tenerindica que la accion se ejecuta en la actualidad, que se ejecu to ayer y seguira ejecutándose en to futuro, en el mismo ca $=$ rácter; por lo que el sentido de la expresión es suficientemen te ilustrativo en lo que a este aspecto se refiere.

De manera, pues, que por ser patrimonial el derecho y recaer sobre una cosa -las minas- éstas son bienes nacionales. Pero, si los bienes nacionales son por clasifica. ción del articulo 589: "bienes nacionales de uso público" y "bienes del Estado o fiscales", segin sea que la facultad de uso corresponda o no ejercerla a todos los habitantes de la na cion, deberían las minas corresponder a una u otra categoría o especie, en definitiva.

Lo cierto es que la clasificación, cuyo fac tor diferencial es el uso generalizado o no, resulta estrechi sima, en relación al bien mina, ya que con respecto a éste, no se puede concebir que corresponda un "uso" general o más particularizado a todos o algunos de los habitantes del terri torio nacional. El criterio expuesto, pareciera tenerse presen te en la obra: "Curso de Derecho Civil" de A. Alessandri R. $Y^{-}$ M. Somarriva U. $\left(^{*}\right)$, por el hecho de que a las minas, como bien jurídico, le corresponde un tratamiento diferenciado en la parte en que se enumeran a vía ejemplar los bienes fiscales -números 145 y 146, del tomo correspondiente a los Bienes y los:Denechos Reales- en lo que se refiere a la categoría bie nes nacionales, sin pronunciarse por su expresa inclusión en Ia especie de bienes fiscales.

De esta manera, siendo Las minas bienes nacionales -mas precisamente, del Estado o fiscales- por la rei terada manifestación de voluntad del constituyente de 1971 y del de 1980, al expresar que: "El Estado tiene el dominio...etc.", conforman una especie o categoría diferente de las enunciadas en los artículos 589 y 590, ya que su régimen juridico de apro vechamiento - generalmente, mediante concesiones mineras y excepcionalmente, mediante los mecanismos indicados en el inciso

(*). - Redactado por A. Vodanovic. 
10 del numero 24 del artículo 19 de la Carta Fundamental- es manifiestamente singular o especial.

De consiguiente, y por lo sostenido anterior mente, sigue manteniendo identidad y vigencia la ubicacion del artıculo 591 en la estructura sistematica del codigo civil.

B.- En segundo lugar, corresponde detenerse en las facultades que entraña el dominio y como se ejercerán por parte del Estado. Cabe indicar, con respecto a esta mate ria, que se debe tener presente que estas facultades se ejerc̄e rán con mayor o menor amplitud, dependiendo la amplitud de las sustancias minerales que contengan los yacimientos y que se consideren como sustancias concesibles o de libre adquisicion en la ley competente al efecto (ley organica constitucional so bre concesiones mineras). De la amplitud de este concepto, eñ el cual se recreará el dominio del Estado, ya hay un claro indicio en la misma Carta Polltica y tanto es asi que el constitu yente ha excluido del regimen de libre concesibilidad o denun= ciabilidad unicamente los hidrocarburos liquidos y gaseosos -primera parte del inciso séptimo-; antecedente por medio del cual se infiere que las sustancias concesibles en el régimen de denunciabilidad serán la mayoría $y$, por tanto, la regla ge neral. Lo contrario sucederá con las sustancias no concesi bles, las cuales serán minoritarias, importando, en consecuen cia, un régimen de aprovechamiento excepcional, desde el punto de vista juridico.

En sintesis, la extension de las facultades del Estado quedarán limitadas a las sustancias que se conside ren no concesibles en el régimen de denunciabilidad que establezca la ley competente y este régimen tiende, en el espiri tu de la norma constitucional, a declarar la mayor cantidad posible de sustancias mineras como concesibles. Por lo demás, el espiritu de la norma se confirma por la ubicación del inci so décimo y último relativo a materias mineras -el cual va dés pués del régimen general que prescriben los incisos séptimo, octavo y noveno-, Inciso decimo que se refiere a las facultades exclusivas del Estado sobre las sustancias no concesibles $y$ otras sometidas a regímenes especiales de naturaleza excepcional en el contexto citado.

En cuanto a la forma misma por medio de la cual el Estado ejercera su dominio, la Constitución Politica ha prescrito en el inciso 10: "La exploracion, la explota ción o el beneficio de los yacimientos que contengan sustancias no suceptibles de concesión, podrán ejecutarse directamen te por el Estado o por sus empresas, o por medio de concesionés administrativas o de contratos especiales de operacion, con 
los requisitos y bajo las condiciones que el Presidente de la Republica fije, para cada caso, por decreto supremo. Esta nor ma se aplicara también a los yacimientos de cualquier especie existentes en las aguas maritimas sometidas a jurisdicción na? cional y los situados en todo o en parte, en zonas que, conforme a la ley, se determine como de importancia para la seguri dad nacional. El Presidente de la Republica podra poner termi no, en cualquier tiempo, sin expresion de causa y con la indem nizacion que corresponda, a las concesiones administrativas o $\bar{a}$ los contratos de operacion relativos a explotaciones ubicadas en zonas declaradas de importancia para la seguridad nacional".

De este modo, surgen cuatro ideas fundamenta les de cómo se podra ejercer el pleno dominio que detenta el Estado sobre las minas $y$, también, sobre los productos o "capi tal" (*) de ellas -como son los minerales que contienen-, sieñ do éstas las siguientes:

a) Que las tres fases de la industria minera, la exploracion, la explotación y el beneficio, todas refe ridas a las sustancias minerales no suceptibles de ser otorga das bajo concesión según el régimen de aprovechamiento delinea do en los incisos 7,8 y 9 (concesión minera coman u ordina ria, que es el régimen general), podrán ser desarrolladas por el Estado en forma global, abarcando toda la industria minera, - bien, ejercitando separadamente cada una de estas etapas por los medios $y$ mecanismos juridicos que se indican a continua ción en la letra d) siguiente, según se crea conveniente. Ello se colige de la utilización de la expresión "podrá", que indica, ciertamente, una facultad o potestad de ejercicio discrecional.

b) El pleno dominio del Estado, se actualiza ra o se ejercera no solamente sobre las sustancias minerales que contengan los yacimientos calificados de no suceptibles de ser objeto de concesion, sino que también se ejercerá, con la misma amplitud 0 intensidad, sobre los yacimientos existentes en las aguas marltimas sometidas a jurisdicción nacional y cual quiera sea la forma en que se presenten (minerales en estado de suspension en las aguas, nodulos marinos, placeres metalrfe ros submarinos, yacimientos existentes en el subsuelo marltimo, etc.), y cualquiera sea la clase, calidad o naturaleza de las sustancias que contengan (metalicas, no metálicas, sustancias concesibles, sustancias no concesibles, etc.). Asi se despren de de la circunstancia de que el constituyente, para fijar la extension del regimen que se comenta, no se ha detenido a observar ni la forma del yacimiento, ni la clasificación del mi-

(*).- Tomada la expresión "capital", en el sentido de sustancias minerales que constituyen la unidad denominada "mina". 
neral que contenga y solamente ha tomado en consideracion la soberania del Estado, bajo la forma de "jurisdicción" sobre las aguas marltimas, quedando, en consecuencia, sometidos los yacimientos $y$ sus minerales que se encuentren bajo aguas de o tro tipo -rios interiores y lagos-, al regimen general o co = man que prescriben los incisos $\% 8$ y 9 de la parte correspon diente a mineria.

c) De la misma manera, los yacimientos, cual quiera sea la forma en que se presenten y sea cual fuere la sustancia mineral que contengan, cuya ubicación geografica, to tal o parcial, se encuentre en zonas que se determine como "dé importancia para la seguridad nacional" por la ley ordinaria competente, estarán sometidos al mismo régimen, como si fueren sustancias no suceptibles de concesion y respecto de las cuales el Estado podra ejercer su derecho en cualquiera de Las cuatro formas básicas que se prescriben en el inciso décimo.

En relación a esta parte, cabe comentar que la declaracion de "zona de importancia para la seguridad na cional" -en los casos que ello ocurra y en el espacio geografico que por tal declaración se cubra- ciertamente, podra com prender, ademas de parte o secciones del territorio nacional continental, partes o secciones de territorio maritimo o de las aguas sometiaas a jurisdicción nacional. Ello es factible, por cuanto el constituyente no ha posibilitado ningun criterio de asignación exclusiva o de limitación y, por otra parte, la expresión positiva que en este caso se comenta, res pecto de la doctrina de la "seguridad nacional", no permitiría limitación alguna del espacio en donde se ejerce la soberania nacional, ya que implicitosestarán comprometidos, seguramente, criterios y factores de subsistencia e independencia estratégi ca, econbmica, etc.

La importancia práctica, que para los efec tos mineros interesa, es la de que las dos formas de actuacion del Estado en que requiere participación de los particulares, como son las concesiones administrativas y los contratos espe ciales de operación, quedarán sujetos a un régimen juridico, en la parte relativa a su extincion, levemente diferenciado a las mismas formas de actuación radicadas en aquellos espacios geográficos en que no se toquen esas zonas. La diferencia se en cuentra en que la misma autoridad concedente -el presidente de la Republica- podra declarar terminada o extinguida la con cesión administrativa minera y terminado, o más propiamente, revocado, el contrato especial de operacion, con la indemnización que corresponda al concesionario o contratante afectado, respectivamente. La decision de la autoridad concedente, la preside la absoluta discrecionalidad, ya que puede adoptarse 
sin expresion de causa y en cualquier tiempo, en la medida que el criterio de caliticacion - de la oportunidad y convenienciade la situación lo permita.

Como corolario de los comentarios de las letras b) $y$ c), puede establecerse lo siguiente: que el Estado e jercerá en toda su amplitud e intensidad el dominio que sobre las minas se prescribe en el inciso sêptimo y que son las ubicadas en las aguas matítimas sometidas a jurisdicción nacional $y$ en los es pacios geograficos que la ley determine que quedan comprendidōs en la declaración de zona de importancia para la seguridad nacional. De la misma manera, se ejercera tal dominio sobre las minas que contengan sustancias no susceptibles de ser concedidas $y$ que se encuentren en cualquier lugar del territorio na cional que no seande los indicados más arriba.

d) Por 氏ltimo, en cuanto a las formas por me dio de las cuales el Estado ejercerá su pleno dominio, resta indicar que podrá ser exclusiva de su persona o bien permitira el concurso de sujetos de derecho privado. Y, además, como se puntualizo, sera facultativo para $\epsilon_{1}$, ocuparse de todas las faenas mineras, algunas de ellas, o parte de ellas, en cualquiera de los sistemas genéricos que prefiera (exclusivo - con participación de particulares) o por particulares que de termine (directamente, por medio de sus empresas o bien por concesión administrativa o contrato especial de operación).

Con el criterio que se viene determinando, cuando el Estado considere que debe actuar en forma exclusiva, 1o hara directamente o bien, por medio de sus empresas. Cuan do requiera el concurso o participación de particulares to ha ra mediante una concesión administrativa o bien mediante la suscripción de un contrato especial de operación.

1.- Con respecto a la primera forma con que actuara el Estado-directamente-, pareciera ser que existen graves obstáculos de Indole operacional, ya que es natural que esta empresa debiera asumirla directamente -idea de serviciosla administracion y esta no tiene la aptitud necesaria para que se traduzca en expedicion y agilidad, elementos que re quiere prioritariamente una empresa moderna. Asi, cada decision, debera revestır la forma de un acto administrativo, ya que es esta la manera cómo se expresa la voluntad de la ad ministracion; los niveles decisorios tenderian a actuar con el esprritu y las motivaciones de los funcionarios publicos, con desmedro sustancial en la eficiencia. Ante los factores apun tados, pareciera más adecuado que la actividad exclusiva delEstado se realice mediante sus empresas, las cuales operarian con cierta autonomía tecnica y financiera, en el marco de una personalidad jurIdica distinta del Estado. Lo anterior posi- 
bilita una polftica operacional más activa, de acuerdo a las exigencias actuales que se requieren a las actividades empresariales. Ciertamente, bajo tal forma ya no existe el engranaje administrativo-publico que, en aras de $\perp$ resguardo, se tor na dilatorio $y$, tampoco, los niveles decisorios estaran imbuí dos del espiritu funcionario, sino que, al contrario, persistiran las motivaciones de eficiencia de efectos incentivadores.

Al margen de las ideas anteriores, las formas participativas de actuación del Estado revestirán especial im portancia, por cuanto se constituiran, ciertamente, en los me= canismos a cuyo uso recurrirá ordinariamente.

Con respecto a la concesión administrativa minera a que se hace referencia en el inciso 10 de la Carta, se supone que no se diferenciara estructuralmente de las otras que se dan en derecho administrativo o publico y presentara sus caracteres mas connotados; vale decir: acto del poder publico-decision unilateral y discrecional-, la reserva de prerrogativas por parte de la autoridad concedente, la precarie dad de los derechos subjetivos publicos que se confieren o constituyen en el concesionario, la temporalidad de los mismos derechos -en especial, las concesiones que inciden en bienes nacionales- $y$, el caráter de acto "intuito personae" que reviste la concesion (cuyos efectos son la "intransferibilidad" e "intransmisibilidad", al margen del parecer de la autoridad concedente). Los elementos que sirven para adelantar esta apreciacion, traducen criterios de preponäerancia absoluta del interes nacional por sobre el interés del partıcular concesio nario, por lo cual el resguardo juridico de tales valores, no podría realizarse mas adecuadamente que mediante un insti-. tuto que revistiera tales caracteres, $y$ que dejare cubiertos Los intereses superiores del Estado concedente.

La misma apreciacion cabe formular respecto de las sustancias no concesibles, ya que detras de la calificación respectiva, existiran prioridades de abastecimiento interno de las necesidades del pass (elementos energeticos, ejem plo: hidrocarburos liquidos y gaseosos) o bien, la tuicion ex clusiva sobre elementos estratégicos (ejemplo: materiales nu= cleares, litio, etc.). En el mismo sentido, la expresion: "....con los requisitos y bajo las condiciones que fije,....." (la autoridad concedente), ha sido suficientemente explicita : en ilustrar el criterio que asistirá a tal mecanismo de opera ción.

puede intentarse una definición de esta especie de concesion administrativa, indicando que ella es un acto administrativo, emanado del presidente de la Reptblica, cuyo objeto sera la exploración, la explotacion o el benefi- 
cio (o en forma global las tres actividades) de los yacimientos que contengan sustancias no susceptibles de ser concedidas, facultando al concesionario para aprovecharse en forma privati va de las utilidades (concesión administrativa minera de explo tacion o de beneficio), que tal actividad sea susceptible de generar.

La autoridad concedente, por propia mencion del constituyente, es el presidente de la Replublica, y su volun tad en tal sentido se expresará por medio de la forma usual que se ha estimado tradicionalmente en nuestro derecho: un decreto supremo. Este decreto supremo debera expedirse para cada una de las concesiones que se constituyan, sin que obste a aquella inteligencia, la circunstancia de que pueda existir una ley ordinaria o general que prescriba los requisitos y ca lidades que deban concurrir en la persona del futuro concesionario y los tactores de apreciación de aquéllos. Esta asevera ción se colige de lo prescrito en la Disposición Segunda Tran sitoria de la Carta Fundamental, al disponer: "Mientras se dic ta el nuevo Codigo de Minería, que debera regular entre otras materias, la forma, condiciones $y$ efectos de las concesiones mineras a que se refieren los incisos septimo a decimo (en es te Gltimo se encuentran tratadas las concesiones administrati vas mineras), del numero 24 del articulo 19 de la constitución Politica de.... etc."

Sin perjuicio de 10 anterior, en cada decre to supremo por medio del cual se otorgue una concesion adminis trativa minera, deberán indicarse los requisitos $y$ condiciones que permitirán la subsistencia del derecho, que por tal acto se constituye, en el patrimonio del concesionario. Al respecto, la autoridad concedente, en juicio discrecional, podra ampliar las condiciones o requisitos o bien restringir los que establece la ley respectiva (probablemente el nuevo código de Mineria), condiciones $y$ requisitos que servirlan de parametros dentro de los cuales oscilaría la apreciación de la autoridad, considerando cada situación en particular. No otra cosa pare ciera desprenderse de la frase: "....con las condiciones y re quisitos que el Presidente de la Republica fije, para cada cā so." La facultad de la autoridad indicada por el constituyeñ te emana de la propia Carta Fundamental, por lo cual deberá tenerse especial consideracion en la discrecionalidad que involucre cada decisión en particular.

En el aspecto doctrinario, esta concesion administrativa minera estaría clasificada como una concesion traslativa de derechos, ya que reconoce, en la persona del con cesionario, las facultades o prerrogativas o parte de aquéllās cuyo antecedente esta, indubitablemente, en el activo patrimonial del sstado. Lo anterior tendría relevancia en la conside 
ración de la extensión e intensidad de cómo el concesionario ejercería el derecho que por el acto de la concesion se le con fiere.

Pareciera ser prudente: en esta oportunidad, ensayar una breve comparación entre la concesión minera "judicial" (.1lanando así a la tratada en los incisos séptimo, octavo $y$ noveno) y la concesión administrativa minera (a la cual se refiere, entre otras materias, en inciso décimo). De tal modo, pueden señalarse los siguientes puntos:

\section{1.- En cuanto a la norma que les sirve de} fuente jurIdica; ambas especies de concesiones mineras tienen su origen en la Constitución Politica del Estado;

2.- En cuanto al caracter, excepcional o no, que ambas especies de concesiones revisten en la institucionalidad minera; la concesión minera "judicial" sera el medio por el cual, ordinariamente, el particular se vinculara con la mineria. Lo contrario se puede afirmar respecto de la concesion minera administrativa, ya que, ciertamente, el mecanismo previsto constituye una situación excepcional;

3.- En cuanto al medio por el cual el Estado manifiesta su voluntad en el acto de otorgamiento; en la conce sıon minera "judicial" - tal como lo indica su adjetivacion- in tervendra el poder Judicial, la Justicia Ordinaria. En la coñ cesion minera administrativa - la misma indicación anterior- in tervendrá el poder Ejecutivo, representado por la persona delPresidente de La Republica. Pero, en ambas, es el Estado el que manifiesta su voluntad, en una u otra torma, interviniendo en su otorgamiento o constitución.

4.- En cuanto al régimen jurıdico aplicable; en las concesiones mineras "juärciales", intervendra un solo, uniforme $y$ objetivo estatuto juridico, conformado, en primer lugar, por lo dispuesto en la parte pertinente de la Constitu ción Politica del Estado en segundo lugar, por las prescripciones de la Ley Organica Constitucional sobre Concesiones Mi. neras (ley $\mathrm{N}^{\circ} 18.097$ ) $\mathrm{y}$, en tercer lugar, por lo dispuesto eñ el nuevo Codigo de Mineria.

En to que se refiere a las concesiones mine ras administrativas, su estatuto juridico estara conformado, en primer lugar, por lo que a su respecto se indica en el inciso décimo de la preceptiva relativa a mineria que establece la Carta; en segundo Lugar, por lo que disponga expresamente el decreto supremo expedido al efecto por el presidente de la Repliblica $y$, en tercer lugar, por 10 que establezca presumiblemente alguna ley especial en la cual se fijen las bases ge 
nerales y factores que debera ponderar, soberanamente, 1 a autori daá concedente $y$, por ultimo, por los principios de Derecho A ministrativo en subsidio de las normas anteriores.

5.- En cuanto al objeto sobre el cual recaerán una y otra; las concesiones mineras "judiciales", recaerán sobre las sustancias minerales que, calificadas de concesibles por la ley respectixa, contenga el yacimiento o mina.

La concesion minera administrativa tambien recaera sobre sustancias minerales que contenga un yacimiento - mina, pero al contrario de la concesion minera judicial, re caera, en primer lugar, sobre las sustancias que se determinén por la ley respectiva como inconcesibles. En segundo lugar, recaera sobre las sustancias contenidas en yacimientos que se encuentren situados, en todo o en parte, en zonas calificadas por la ley como de importantes para la seguridad nacional. En tercer lugar, las concesiones mineras administrativas, recaerán sobre las sustancias minerales que se contengan en yaci mientos que se encuentren situados en el territorio marftimo o. sea en aguas sometidas a jurisdicción nacional;

6.- En cuanto a la procedencia de indemnizaciones una vez extinguidas; la concesion minera judicial cuyo respecto ha operado la caducidad o la simple extincion del dominio, no origina indemnización alguna a favor del titular afectado por ella; salvo en cuanto se haya extinguido sola mente en su patrimonio el dominio y en virtud de un acto de ex propiacion, realizado en conformidad a los incisos 3,4 y 5 del numero 24 del articulo 19 de la Constitución. La concesion minera administrativa, cuando se extingue por la llegada del plazo u otra condición prevista en el decreto supremo constitutivo, ciertamente, no autorizara para pedir indemnización al guna. La situación contraria ocurrira, probablemente, cuando sin intervenir las hipotesis previstas para su caducidad o ex tinción, el Presidente de la República ponga término, en cuaIquier tiempo y sin expresión de causa, a las concesiones mine ras administrativas relativas a explotaciones ubicadas en zo= nas declaradas de importancia para la seguridad nacional. Esta particular situacion esta prevista en el texto constitucio nal, en el inciso decimo Gltima parte de la preceptiva que sē refiere a minería.

7.- En cuanto a la caracteristica del titu10; 1a concesion minera judicial es un instituto revestido de las seguridades suficientes como para convertirse en un real incentivo a la expansion productiva del sector. De alli, pues, que se le haya definido como un derecho real, inmueble (artículo $2^{\circ}$ de la ley numero 18.097) y que la propia Consti 
titucion, en el inciso noveno del numero 24 del articulo 19, haya dicho que, sobre esta cosa incorporal que es el derecho de concesion, el particular ejerce dominio, estando amparado este mismo dominio por la garantra del numero 24 .

8.- En cuanto a las especies que comportan una $y$ otra categoría de concesiones mineras; la concesion mine ra judicial, reconoce dos especies solamente, siendo ellas: a) la concesión minera de exploracion, y: b) la concesión mine ra de explotación. La concesión minera administrativa, siem= pre en el terreno de las suposiciones con respecto a ésta, pro bablemente tendra tantas especies como lo requiera la oportunidad y conveniencia, en cada situación particular que se presente. Ello se colige de que con respecto a las sustancias concesibles, el Estado "podrá" o conceder la exploración, la explotación o el beneficio de ellas.o, si lo prefiere, dado el caso, solo parte de alguna faena mencionada o todas ellas. En definitiva, las situaciones juridicas creadas podrán ser multiples y variadas, dependiendo de las necesidades y la opor tunidad y conveniencia, a juicio discrecional de la autoridad concedente.

La otra participativa del Estado estara da da por la celebracion de contratos especiales de operacion, contratos que se adjetivarán según fuere la sustancia mineral objeto jurídico del acto. (*)

Los contratos de operación, o de riesgo como también se le conoce, representan el mecanismo juridico de res puesta de parte de los países que exhiben un menor grado de dé sarrollo relativo, en resguardo de sus intereses economicos $y^{-}$ ante las motivaciones, intereses $y$ actividad economica desarro liada fundamentalmente en el seno de las economias de estos paises, por los inversionistas cuyo capital es de origen exter no.

El contrato de operación es un genero que tiene variadas especies, dependiendo ellas de cada mineral $y$ situacion particular. Lo mismo ocurrira con los derechos $y$ o bligaciones que en cada especie de contrato asuman las partes. Este caracter queda de manifiesto en la legislación peruana de la especialidad, Decretos Leyes numeros 22.774 y 22.775 de 7 de Diciembre de 1979, por nedio de los cuales se altera fun damentalmente el régimen y variedad de celebración de estos contratos en materia petrolifera, $y$ ante la rigidez manifestada por la legislacion anterior, de principios de la decada.

$T^{*}$.- Un tratamiento sistemático, relativo a una especie de estos contra tos legislado en Chile, puede verse en: "El Contrato de operación sobre Materiales Atómicos Naturales" de Pablo Sáenz de Santa María M. Memoria de Prueba: U. De Chile, no publicada, 1979. 
En nuestro derecho, al menos por ahora, se conocen dos tipos de contratos, siendo ellos, los que se refieren a los hidrocarburos - decreto ley numero 1.089 de 1975Y a los materiales atómicos naturales - decreto 1ey nímero 1.557 de 1976-. Ambos cuerpos legales constituyen la legisla cion básica en vigencia en nuestro pais.

El contrato de operación o de riesgo puede decirse que es una convencion entre el Estado y un particular, por medio dela cual el segundo se obliga a realizar labores de exploración (principalmente), explotación o beneficio de una determinada sustancia mineral $y$, si obtuviere resultados positivos (exploración particularmente), el primero retribuirá en dinero o en especie (según la satisfacción de las necesidades internas del Estado-parte), la labor realizada por el segundo, soportando éste las pérdidas en el evento de un resultado negativo de las faenas u operaciones contratadas.

\section{El objeto fundamental de estos convenios,} son las faenas de exploración de nuevos yacimientos, pudiendo pasar a las etapas posteriores de "aprovechamiento" o "explotacion", en la medida de:que obtengan resultados positivos, $y$ lo acuerden, según la conveniencia de las condiciones, las partes contratantes. Cabe hacer presente que la etapa poste rior, de explotación, se encuentra prevista, normalmente, en el instrumento mediante el cual se ha celebrado el contrato especial de operacion de "exploración".

En cuanto al contenido del convenio, se pue de decir que las obligaciones asumidas por el Estado contra= tante, basicamente, se refieren a los siguientes puntos: la invariabilidad de la legislacion, especialmente la tributaria, arancelaria, aduanera, etc. En este aspecto se conside ra generalmente la mantencion del tipo de cambio; franquiciās en la internación y repatriación de capitales, etc.; la obligación de respetar el derecho prioritario, en el evento de que obtenga resultados positivos en las faenas de exploración, 'pa ra vincularse preferenternente a las posteriores de explotación y beneficio de la sustancia de que se trate; de pagar en dinero o en especie - la sustancia mineral descubierta- la labor de resultados positivos realizada por el otro contratante, etc. Por otro lado, la empresa particular, asumira las obligaciones de contratar personal o mano de obra perteneciente al pars de las operaciones; capacitar a este personal en el manejo de tecnologra, sistemas y procedimientos administrativos $y$ también, si fuere del caso, en el conocimiento, opera ción y estrategias de comercialización de la sustancia minéral de que se trate; a hacer transferencia de tecnolgra; tam bién se obliga a desarrollar de una manera efectiva y comple ta las faenas mineras a las cuales se comprometio por su cuen 
ta $y$ riesgo, sin que los resultados negativos afecten al Estado contratante; el sometimiento a los tribunales -especiales $u$ ordinarios- de la jurisdicción del pass contratante pa ra los efectos de la solución de las controversias a que de origen el contrato, etc.

Los derechos de cada contratante, resultan de las obligaciones que haya contraido la contraparte.

En cuanto al régimen de constitución, es bien explrcita la Carta al señalar, al igual que para las con cesiones administrativas mineras, que se requiere de un decrē to supremo, expedido para cada caso, -en esta situacion, pară cada contrato- por el Presidente de la Republica, decreto supremo en el cual se debera contener los requisitos y condicio nes del contrato de operacion de que se trate.

En síntesis, el inciso decimo trata de los mecanismos de que esta provisto el Estado para los efectos del ejercicio $y$ aprovechamiento de su derecho de dominio sobre las minas. De la misma manera, establece las faenas basi cas a las cuales podran referirse los mecanismos que el Esta do considere oportuno implementar, $Y$ se extiende el ejexcicio del derecho de dominio en forma considerable, al señalar que el mismo régimen se observará respecto de los yacimientos que se encuentren en aguas maritimas sometidas a jurisdicción nacional $y$ a aquellos yacimientos ubicados, en todo o en par te, en zonas que en conformidad a la ley se determinen como de importancia para la seguridad nacional.

Cabe indicar que con la dictacion de la Ley organica Constitucional sobre Concesiones Mirieras, el legislador de la especialidad ha recabado un requisito que se encuentra mucho más alla del texto y espiritu de la norma cons titucional que prescribe el inciso décimo del número 24 delartículo 19 de la Carta. Éste se refiere a que la ley que fi. je o declare la o las zonas de importancia para la seguridad nacional, deberá tener la calificación expresa de ser "con efectos .inineros".

La exigencia a que se alude está de más $Y$ no se justifica, ya que resulta natural que si una ley declara tales o cuales zonas como de importancia para la seguridad nacional, implícita en tal declaración estarán compro metidos, ciertamente, factores como la soberanía nacional y otros y, daäa su magnitud, es que el constituyente no ha con siderado necesario establecer calificación alguna, para que. los derechos que se ejerzan en esas zonas se guien por las prescripciones que ha estimado fijar en el referido inciso. 
De esta manera, se confirma la excepcionalidad que en el conjunto de instituciones economicas, presen ta el sistema de organización minera elegido por el constitu yente en nuestro pais. Pero, por otra parte, la amplitud dél espacio maritimo, dentro de cuyos limites la vinculacion domi nical del Estado desplegara toda su extension e intensidad (territorio nacional que excede en proporciones al continental), no resulta ser tan excepcional el dominio pleno del Es tado, mirada la situacion desde una perspectiva territorial.

Queda por realizar un Gltimo comentario relacionado directamente con el tema que se analiza y referido a la posibilidad de que el Estado, cuando le interesen deter minadas sustancias de las calificadas como concesibles por la ley respectiva, pueda obtener "concesión minera" - de la que tratan o se refieren los incisos 7,8 y 9 del numero 24 del artrculo 19 -sobre aquellas sustancias;al igual y en la misma condición que los sujetos particulares. El interés surge por el hecho de que se ha mencionado esta posibilidad, en el evento de que el Estado se encuentre interesado en "ad quirir derechos mas especificos aú (se supone del dominio pleno que tiene en su patrimoniol, más cercanos al objeto." . (*)

Por de pronto, en el plano de los principios juridicos desarrollados en materia minera por el constituyen te, resultaría ciertamente contradictoria tal posibilidad. Ello se explica, si se tiene presente que el Estado tiene un derecho de dominio pleno -que implica tanto la existencia de las facultades de uso $y$ goce como el ejercicio de tales facultades sobre la mina misma, como sobre los elementos que ella contiene $-y$ mal podrra, recurriendo a la legislación complementaria, en calidad de sujeto privado, recabar para sI, lo que en esencia es un derecho en cosa ajena-la concesión minera-, siendo que ya posee en su activo patrimonial, a tItulo de dominio, las facultades y prerrogativas que tal su puesta nueva investidura es susceptible de proporcionarle.

El problema resulta clarisimo, respecto de los yacimientos de cualquier especie y forma que se encuentren en las aguas marrtimas sometidas a jurisdiccion nacional $y$, también, respecto de aquellos yacimientos cuya ubica cion, de alguna manera, se encuentre en zonas declaradas como de : importancia para la seguridad nacional. Lo mismo cabe decir respecto de las sustancias que se consideren no conce sibles.

(*).- José Piñera E., ob. cit., en cuanto al problema del acercamiento del Estado al objeto minero, acercamiento que sólo podría realizarse por una de las tres vías que se mencionan, siendo una de ellas: "la obtención de concesión minera sobre sustancia concesi ble". 
Se pierde la diafanidad en relación a las sustancias que se estiman concesibles por la ley respectiva. Antes de la interpretacion constitucional de 1971 -reiterada en la nueva manifestacion constitucional de 1980-, tal situación no presentaba problemas de orden fundamental a in cuando si accesorios (*), debido a que se entendía, por la interpretación de los artículos 591 y $1^{\circ}$ del Codigo Civil y de Minería, respectivamente, que el Estado, por la tenencia del dominio eminente o radical, no era capaz, por la sóla circunstancia men cionada, de desplegar una facultad patrimonial; cosa que al contrario ocurría con la pertenencia definida en el articulo $2^{\circ}$ del Codigo especial del ramo. El Estado requería bajo la vigencia de tal interpretación, de otras instituciones del de recho de minería, como eran la reserva de ciertas sustancias -mencionadas en el artículo $4^{\circ}$-, la no inclusión de alguna de ellas en la nomina de sustancias denunciables y la adquisicion de derechos mineros por propia concesion, entre otras (compra, donaciones, etc.).

Ante el cambio radical del sentiido de la in terpretación que se daba a los articulos mencionados, resultā ciertamente riesgoso aventurax el mismo mecanismo de vincula ción para el Estado, sobre todo cuando los principios sobre los cuales se asentaba han variado en forma tan manifiesta.

La solucion ante tal interés que posiblemente manifieste el Estado y siempre en el orden de los princi pios, pareciera dilucidarse al verificar con toda exactitud la naturaleza y función que cumple la norma que fija la denunciabilidad de las sustancias mineras frente al dominio que deten ta el Estado. La blisqueda podría centrarse en el aspecto de si tal nomina de sustancias implica un requisito adicional pa ra el ejercicio del dominio del Estado con respecto a estas sustancias "denunciables" 0 , mas propiamente"concesibles". Asi, por vía de consecuencia, podría determinarse de que natu raleza es la "renuncia a la concesion", que consagra la legis lación vigente $(* *)$. Si tal acto de renuncia fuera "abdicatí vo", quedaría el bien como "res nulius", pero, siendo un inmue ble, tal situación no podría darse -artículo 590 del codigo Civil- y siempre este bien se encontraría en el patrimonio del

(*) .- Al respecto, puede verse un ilustrativo y riguroso análisis en "El dominio del Estado sobre las minas" de Enrique Escala Baltra, en que se analiza el problema a la luz del principio de la "especia lidad" y de "la capacidad" del Estado. Memoria de Prueba para op tar al Grado de Licenciado en Ciancias Juridicas y Sociales, 1965.

$(* *)$. - Decreto Ley Número 1.759, artículo 7. 
Estado. De este modo, detrás de cada acto de renuncia existiria en una forma implícita, una reversion de derechos al Estado, de acuerdo a la legislación en vigor. Por lo anterior, resulta difrcil deducir, en el plano indicado, que pueda darse la posibilidad de que el Estado sea dueño de un derecho real de goce o aprovechamiento - la concesion minera- por propia autoconcesion y sobre bienes del mismo Estado.

II.- DURACION, DERECHOS Y OBLIGACIONES DE LA CONCESION MINERA.

El elemento duración de la concesión minera, particularmente el referido a la de explotación, es uno de los puntos que ha causado dudas en orden a determinar su exten sión en el trámite de aprobación y discusión de la ley 18.097.

Las posiciones sobre el punto se resumen en dos ideas basicas: la primera, se fundamenta en la circunstancia de que cuando la Constitucion otorga competencia a la ley orgánica respectiva para que, entre varias otras cosas, deter mine la "duracion" de la concesión minera, en forma implicita, se está refiriendo a la fijación de un plazo o "término". E110, se estima, es consecuencia del sistema que positivamente ha indicado el constituyente para la organizacion del régimen de derechos mineros, ya que teniendo el Estado un dominio perpetuo sobre todas las minas, necesariamente los derechos en co sa ajena -el derecho de concesion minera es uno de ellos- de-berán ser temporales, de acuerdo con los principios que infor man tales derechos. De esta manera, la exacta competencia que tendria el legislador de la especialidad, se circunscribirra a fijar la "unidad de tiempo" -plazo o término-, que durara la concesion minera como derecho y sea que la especie lo fuere de exploracion o de explotación.

De otra parte, $y$ concordante con lo anterior, se ha estimado que teniendo el Estado sobre todas las minas un dominio absoluto, imprescriptible y, especialmente, si ese do minio es, además, "exclusivo e inalienable", mal pudiera constituirse un derecho en favor de terceros que tuviera un carác ter indefinido o bien perpetuo, sobre el mismo objeto o las $\bar{u}-$ tilidades materiales que sea capaz de producir. $Y$ as 1 resulta ser -se agrega- en relacion con las minas, ya que el otorgamiento de un derecho con el caracter de indefinido, como lo hace el articulo 17 del proyecto de ley respectivo (conserva la misma ubicación en la norma actualmente publicada), significa la extension de ese derecho, en el tiempo, hasta la ex $\leftarrow$. tincion o agotamiento de la mina misma, lo que equivale, en buenas cuentas, a la enajenación o transferencia del dominio, 
acto que de ningún modo esta permitido. Analoga situación, en el aspecto jurrdico, podrra presentarse en una administra ción en que se estimara que no existe deber de rendir cuentäs - en el contrato de arrendamiento cuya duracion sea indefinida $y$ sin obligación de restituir por parte del arrendatario.

La segunda corriente de opinión, cuyas ideas el Tribunal Constitucional acepto en definitiva, estima que si bien la Constitución confiere al derecho del Estado tales caracteres, no es menos cierto que ese derecho se encuentra 1imitado acto seguido en la misma Carta, al establecerse "la con cesion minera". Se agrega que si se ha otorgado competencia para fijar la "duración", ello faculta al legislador para hacer el derecho de concesion minera de tiempo indefinido, pues el concepto de "duración" es de mayor amplitud que el de "plazo".

Las consideraciones que el Tribunal Constitu cional tuvo en vista para decidir el sentido del fallo en el punto que se comenta, esto es, declarar que la "duracion indefinida" de la concesión minera de explotación no infringe la Constitucion politica del Estado, parecieran ser confusas y contradictorias $y$, además, opuestas al texto $y$ espiritu del rê gimen sobre concesiones mineras dispuesto por la normativa. Esta consideración se colige de los siguientes hechos:

1.- Cuando el Tribunal Constitucional fija el sentido de la expresion "duracion" (en el considerando octavo del fallo), infiere, previo recorrido por el Diccionario de la liengua, que esta expresión puede ser "a término cierto - incierto" $Y$, agrega, que al expresar la ley que la concesión tendra una duración indefinida, estableció que su permanencia en el tiempo (la del derecho de concesión), "no queda determi nada." Respecto de las deducciones anteriores cabe señalar y" puntualizar lo siguiente: cuando por el Tribunal Constitucional se ha inferido que la duración puede ser "a término cierto o incierto", debe entenderse en forma natural, de acuerdo a una estricta apreciación jurílica, que lo que se ha querido indicar por el 6rgano, es que ella puede ser a "plazo" (no otra cosa se deduce äe la utilización de la expresión "térmi no"), plazo que puede ser "cierto o incierto" como se encarga de puntualizar la misma fuente (lo que caracteriza al plazo, entre otras cosas, es el factor certidumbre $y$ éste es el elemento que lo diferencia de las condiciones, que es otra de las modalidades que pueden modificar los efectos de un acto juridicol.

Pero, es bien claro que un plazo "incierto" (que no se sabe si realmente ocurrira) sólo tiene de "plazo" el nombre, puesto que, siendo hasta un dra incierto e indeter 
minado, segun los artículo 1083 y 1086 (*) del codigo Civil, se califica de "condicion" y se sujeta, como corresponde, a las reglas que gobiernan ésta.

Se afirma que un plazo de "duradión indefini da" tiene de plazo tan solo el nombre, porque en derecho: "lás cosas son lo que son y no lo que se dice que son" $y$, aún más, el mismo Codigo Civil, en los citados artículos, observando la naturaleza de las cosas, determina que tales plazos son "condi ciones" $y$, por tanto, deben guiarse por las reglas aplicables a éstas.

Al estimar el Tribunal Constitucional que "duracion" significa "término" (plazo), se entiende que sobre esta particular modalidad deberá proceder a discurrir. Pero, dentro del concepto de."plazo" debe desecharse, por no corres ponder a la naturaleza del requerimiento constitucional, la consideración de un plazo cuyo caracter sea "incierto", y debe desarrollarse o desenvolverse el razonamiento en el plano de un término "cierto" (es decir: "hasta un dia cierto, determinado o indeterminado"), ya que de lo contrario, al aceptarse que pueda ser un plazo "incierto", que es condicion (hasta in día incierto e indeterminado), no se estaría cumpliendo por la ley respectiva, en la parte comentada, con el mandato expreso de la Constitución y lo más grave, no se estaría siendo conse cuente con las bases en que se está asentando el discurso qué tiende a determinar el sentido de la expresion "duracion".

Por otra parte, la Constitución no podria re querir de un "plazo" con estas características, ya que expresa mente ha estimado necesario fijar una condición, cuyo acaecimiento, determina "la caducidad" del derecho de concesion, en el caso de incumplimiento de los requisitos de amparo. Resul ta, por consiguiente, inverosimil pensar o suponer que el cons tituyente haya estimado la expresion "duracion" en el sentido de "condicion", tal como aparece del razonamiento del Tribunal Constitucional.

2.- El Tribunal Constitucional al establecer la idea anterior en el primer considerando relativo al punto controvertido, los siguientes los desarrolla en términos igual mente confusos, como es el caso del considerando numero 9, en que se estima: "que si el constituyente hubiere querido limi-

(*).- El Art. 1083 citado determina: "El día incierto e indeterminado es siempre una verdadera condición y se sujeta a las reglas de las condiciones." Por su parte, el Art. 1086, establece: "La asignación desde un día incierto, sea determinado o no, es siempre condicional....." 
tar la concesión en el tiempo (*), imponiéndole un plazo, lo habria dicho. Notese que el mismo Tribunal Constitucional ha bía determinado en el considerando 8, que "duracion" signifi= ca "termino", lo cual constituye un plazo.

\section{3.- En el considerando 9 se indica, que se} debe tener presente que hasta la época de "dictacion" (segura mente se refiere a la vigencia de la Carta), de la actual coñs titución, el derecho a explo ar minerales gozaba de "duración indefinida". Al respecto, basta recordar que "el derecho a explotar minerales" a que se alude, está reglamentado en el có digo de Minerla de 1932 ("la pertenencia minera") y sigue vi = gente hasta la fecha de publicacion del nuevo Codigo de Mineria. Por otra parte, la interpretacion (sentido mayoritario) de los articulos $1^{\circ}$ del código de Minerfa y 591 del Codigo $\mathrm{Ci}$ vil, que fijaban el sistema de organizacion minera, era de un sentido diametralmente opuesto al fijado por la interpretacion constitucional de 1971 y reiterada, en los mismos térmi nos, por la Carta de 1980. En consecuencia, no corresponde considerar lo dispuesto en dicho cuerpo legal (Codigo de Mine ría de 1932) como elemento de juicio para fijar el alcance dé la "duracion" de este derecho, sin que se incurra en un gravi simo desconocimiento de la evolución de nuestro derecho tanto desde un punto de vista constitucional como desde la especialidad de la materia. Confirma lo anterior, la circunstancia de que una vez fijadas nuevas normas básicas por la ley 17.450 de Julio de 1971, se haya considerado conveniente dictar un nuevo cuerpo legal (Disposición Transitoria Decimosexta), en reemplazo del Código de Minería de 1932, para los efectos de desarrollar los principios y reglas que se desprenden de la nueva normativa constitucional y que se espera hace ya más de una decada. Lo dicho vale, en igual forma e intensidad, respecto de la Constitución Polrtica vigente (Disposicion Transi toria Segunda).

De este modo, la frase final de este conside rando 9, que infiere: "si se hubiese querido innovar, se ha bría usado vocablos precisos...." carece de base juridica tan to desde un punto de vista sistematico como contextual, ya que no corresponde estar requiriendo detalles de una norma, cuya técnica básica de construcción indica que sus prescripciones deben ser, precisamente, reglamentadas en una ley con el carác ter de "orgánica constitucional", que, por algo, tiene aquellá denominación. Esto se comprende porque la Carta, atendida su especial naturaleza, solamente está llamada a fijar las bases

(*).- El Tribunal Constitucional se refiere a la -oncesión en forma genérí $\mathrm{ca}$, por lo que es de suponer que sus razonamientos son plenamente aplicables tanto para la concesión de explotación como para la concesión de exploración. Esta deducción está de acuerdo con lo dispues to en el artículo $1^{\circ}$ de la ley número 18.097. 
de las instituciones $y$, en este caso, el de la especialidad minera.

4.- Én lo que respecta al considerando décimo, en el sentiảo de que el dominio del Estado no cambia por el hecho de que la concesion sea a plazo o de duración indefi nida, resta por hacer presente que se debe tener especial coñ sideración respecto de la concesión misma, y ésta, siendo un derecho real en cosa ajena, se caracteriza por la temporalidad en el sistema de nuestro derecho $y$, ciertamente, en el derecho universal. AsI, puede citarse el derecho real de usufructo, que con la concesión minera tiene una fundada semejanza (ar tículos 764 y 806 número 1, del Código Civil); el de uso $y$ ha bitación (artículos 811 y 812 del mismo cuerpo legal). Ade = mas, al respecto, debe tenerse presente lo que disponia el An teproyecto de 1 Codigo de Minería (documento inédito), en su artrculo 73, correspondiente al Titulo VI, denominado: "De la condicion juridica de las concesiones de explotación", al pres cribirse: "La concesion de explotación, se entendera otorgada por el plazo de treinta años, contados desde la fecha de la inscripcion del acta de mensura y prorrogable por iguales pe-i ríodos hasta un máximo de noventa años.", (inciso primero).

5. - La misma objeción corresponde formular respecto de los siguientes considerandos:

a) Numero 11.- En que se confunde la "condi cionalidad" de la concesión (régimen de amparo), con la "durâ ción" de ésta (*) que por propia interpretación realizada en el considerando número 8, implica un "plazo o término".

b) NGmero 12.- En que se vuelven a confundir las dos entidades, ya que las causales indicadas para la termi - nación, como ser, la caducidad (que es expresión del régimen de amparo, por propia mención del inciso séptimo de la Carta) y la expropiación (que es una de las expresiones de la sobera nía del Estado sobre todos los bienes que se encuentren en su territorio; y con respecto a los cuales puede utilizar la expropiación como medio jurídico, para los efectos de incorporar los a la categoría de aquellos bienes sobre los cuales puede ejercerse un dominio efectivo, medio que al efecto permite em plear la Carta en los incisos 3, 4, 5 y 6 del numero 24 del āx ticulo 19), nada tienen que ver con la "duracion", que como $e=$ lemento esencial de la concesión prescribe la Carta.

(*).- La "duración" a que alude la Carta también extingue la concesión mi nera, sea ésta de exploración o de explotación, pero ello ocurre a consecuencia de que ha llegado o se ha cumplido un plazo, a diferen cia de la "caducidad" que aun cuando también extingue la concesión, 
6.- El Tribunal Constitucional, en otra par te de su fallo (ntumeros 3 y 4 del voto de prevencion de los $\bar{m} \underline{1}$ nistros señores Correa y Ortuzar), vuelve a incurrir en las mismas confusiones y en que, ademá, se declara que la ley res pectiva "cumple" con el mandato constitucional de fijar la dur ración de las concesiones (numero 3 ).

7.- Como Gltimo comentario relativo al punto, es necesario hacer presente que las mismas consideraciones hechas en relación a la "duración" de la concesión minera de explotacion, también son aplicables en toda su extensión e intensidad a la concesión minera de exploración, por cuanto, en lo que se refiere al texto constitucional, en el inciso septimo no se ha hecho diferenciación alguna relativa a la materia, por lo que, al intérprete no le corresponde distinguir (cualquiera que este sea, inclurdo el legislador que intervino en la dictación de la Ley orgánica de referencia y el mismo Tribu nal Constitucional) el tratamiento dado a una $y$ a otra. En es ta parte, resulta inexplicable el criterio del Tribunal Constí tucional, al no haber hecho observación alguna en lo relativo a la "duración" de la concesión minera de exploracion, tratada en lo que a este aspecto se refiere, en el articulo 17, primera oración, de la Ley, en que se determina que la concesión de ex ploración "...no podrá tener una duracion superior a cuatro años; ..." Cabe estimar que: "donde existe la misma razon, debe existir la misma disposicion", que resuelva el problema de la especie. Ello, en definitiva, no ha ocurrido as 1,10 cual es desde todo punto de vista lamentable.

En síntesis, la ley competente respectiva "ha fijado la duración de la concesión minera de explotación, bajo la forma de un plazo de caracter incierto, de tiempo indefinido, con lo cual, habida cuenta de las observaciones jurídico-técnicas anteriores, realmente no ha cumplido con el mandato expreso de señalar "la duración" que impone al legislador el inciso séptimo.

( ).- sin embargo, ello ocurre por el hecho de que ha operado una condi ción resolutoria, esto es, por el hecho de haberse dejado de cum plir la condición de amparo, antes de que se produzca la termina ción por la llegada o cumplimiento del plazo. 